\title{
From Brand Management to Global Business Management in Market-Driven Companies*
}

\author{
Emilio Zito $^{* *}$
}

\begin{abstract}
Over the past several years, the most competitive mass-market companies (automobile, high-tech, consumer and retail, etc.) have been experiencing a new strategic approach around the concept of Market-Driven strategy, as opposed to a pure marketing-focused approach known as Customer-Driven strategy.

A fast-moving, mass-market global company would likely have a precise performance measurement system in place with broad performance indicators based on: project economics, ratios analysis (ROI, inventory turnover, etc.), risk management, shareholders' value analysis, synergies forecasts (economies of scale, scope, learning, etc.), market share, customer and retailer satisfaction.

Therefore, the management structure will be focused on brand and product global strategies involving a new type of operational manager: the global business manager.
\end{abstract}

Keywords: Globalisation; Market-Driven Management; Market-Driven Companies; Global Companies; Global Business Management; Brand Management; Product Management

\section{Market-Driven Companies}

Over the past several years, the most competitive mass-market companies across a wide range of industries (automobile, high-tech, consumer and retail, etc.) have been experiencing a new strategic approach around the concept of Market-Driven strategy, as opposed to a pure marketing-focused approach known as CustomerDriven strategy. In the current market economy, the role of Market-Driven management is to create, develop and sustain added value solutions helping and affecting the primary market actors (community, individuals and organisations) to

\footnotetext{
* Invited Article

*** Merger and Acquisition Manager, EDF - Electricité de France, Paris (emilio.zito@edf.fr)
}

Edited by: ISTEI - University of Milan-Bicocca

ISSN: 1593-0319

Zito Emilio, From Brand Management to Global Business Management in Market-Driven Companies, Symphonya. Emerging Issues in Management (symphonya.unimib.it), n. 1, 2009, pp. 4953

http://dx.doi.org/10.4468/2009.1.05zito 
efficiently face issues and needs. This approach highlights the fact that a competitive company should be driven by the market as a whole, including customers and trade on the one hand and competitors and other strategic stakeholders on the other one. Such a strategy allows companies to focus on their final products and/or services in a competitive way by looking at what the market potentials are out there and the way those potentials can be best exploited, controlled and developed.

\section{Brand Management in Market-Driven Companies}

A Market-Driven strategy follows the necessity for companies operating in global landscapes to cope with fast-moving market conditions based on a clear and structural excess of supply over demand. To put it another way, it becomes crucial for fast-moving, mass-market companies to retain and boost any competitive advantage they have by quickly adapting their international strategy and internal organization to best reflect the evolution in market strategic drivers and critical stakeholders.

For such companies, some of the most common strategic drivers are:

- Brand (product, positioning, pricing, competitors, communication, etc.);

- Final customer and Trade (CRM, incentives, marketing strategy, market research, etc.);

- Suppliers (supply chain strategies, vertical integration, outsourcing, etc.).

Following upon these main strategic drivers, on a brand/product analysis level, a fast-moving, mass-market company is likely to have some of its most standard performance indicators based on: full market share, revenue, fixed and variable costs, operating margins analysis, customer and trade satisfaction.

As far as its internal organization is concerned to support such a strategic approach, the management structure is mainly focused on brand and product strategies involving, on an operational level, brand and product managers.

The decision-making process can be quite hierarchical as functional top managers and executives cascade down the requests and tasks following a 'top down' approach. The first step in the information flowing mechanism turns out to be pretty efficient, meaning information usually flows timely and effectively among senior managers and executives, on a non-operational level interaction. The second step in the information flowing mechanism comes when the job request and all related pre-analysis information (e.g. starting a product analysis, comparing positioning with competitors, studying the feasibility of a new brand/product launch, analysing a new market entry, just to cite some) will be cascaded down to operational-functional managers to get analysed and executed.

The risk here is that the information flows may be heavy and at times pretty slow as the interaction between operational and top managers is not based on an day-today relationship and their 'distance' might sometimes determine a loss of information. Following this interpretation, information will be entirely managed on a top, non-operational level and cascaded down according to a precise functional consideration. 
A very simple and illustrative example of such a 'top-down' information flows within a fast-moving, mass-market company could be: marketing senior management exchanging with finance senior management about the feasibility of launching a new brand into the market. Marketing senior management will then cascade the pre-analysis marketing information down to brand/product managers. The same will happen with the finance senior management concerning the financial objectives related to the specific job request (see Figure 1). Brand/product managers and finance managers will then perform their analysis by focusing on their specific function and role and will then hand their results up to their senior management.

Figure 1: Brand Management in Market-Driven Companies

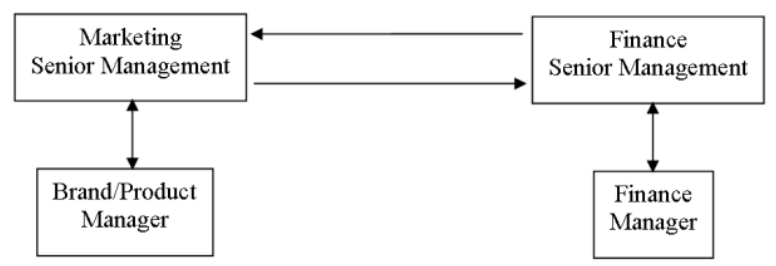

\section{Global Business Management in Market-Driven Companies}

Mission, culture, strategic drivers and internal organization represent for an international company some of the most important milestones, determining the company's strategy on a worldwide dimension. Multinational approaches usually trigger 'Glocal strategies' characterized by strong local market adaptation and significant change management capability. The challenge for fast-moving, massmarket multinational companies stems from the fact that standard Glocal strategies might not be enough in the current global environment to allow companies to retain and/or differentiate their competitive advantages.

Some of the reasons for that are: markets and stock exchanges are becoming increasingly global and volatile; customer loyalty is getting very complicated to maintain and/or influence; the extreme rapidity in market strategic drivers and stakeholders evolution makes difficult for companies to efficiently manage the change; and the list does not clearly stop there.

That said, some of the most competitive, market-driven companies are being adjusting their strategy towards a more complicated and flexible 'strategic metrics' to reflect the fastness of the change and development in their main strategic drivers and global stakeholders. To put it another way, some more market strategic drivers would be added to the ones mentioned above, in particular:

- Shareholders

- Financial Community (creditors and/or banks, stock exchanges, financial analysts, rating agencies, journals, etc.).

Following upon this more-mixed strategic drivers approach, a fast-moving, massmarket global company would likely have a precise performance measurement system in place with broad performance indicators based on: project economics and 
cash flows analysis (full project profitability, NPV and break-even analysis, IRR, cost of capital, etc.), ratios analysis (ROI, inventory turnover, etc.), risk management, shareholders' value analysis, synergies forecasts (particularly with regard to brand/product acquisition: economies of scale, scope, and learning, etc.), full market share, customer and trade satisfaction.

By performing such a factual analysis, an organization will make the 'strategic metrics' the tool to make decisions rapidly and efficiently. Strategic drivers are the granularity which determines the 'strategic metrics', heavily affecting the way internal organization and management focus will be built up. Therefore, the management structure will be focused on brand and product global strategies involving a new type of operational manager: the global business manager.

The very main reason for a manager to be a global business manager comes from his/her capability to have a 'global' professional knowledge, including marketing, strategy and finance broad knowledge. He or she will need to have a clear vision on 'where to go' and 'how to get there', being able to: 1) understand the changing strategic drivers, 2) absorb scorecards and strategic metrics methodologies, 3) build and lead skill-mixed operational teams, and so on.

The decision-making process will be much less hierarchical compared to the previous 'top-down' structure. As a matter of fact, there will probably still exist functional top managers cascading down the requests and tasks. The difference here is the direct participation of the operational management (through global business managers) in a higher level strategic discussions making them able to play a role more of an assembler of information rather than of an executor of functional requests.

This follows a 'bottom up' approach and a matrix organisational structure as opposed to a functional organisational structure in the more standard case of functional managers and the 'top down' approaches. Practically, information will timely flow among senior managers and executives on the one hand and global managers and their teams on the other hand. Such a 'bottom up' approach will likely: 1) streamline the overall organisational structure and decision-making process; 2) centralise the operational management by getting them closer to the decision-making process; and 3) help a Corporation to have an efficient internal organisation.

A very simple and illustrative example relative to the information flowing mechanism in such a situation may be the following: marketing senior management exchanging with finance senior management the feasibility of launching a new brand into the market. Senior managements will have a direct operational person, the global business manager, to speak to and begin a pre-analysis interaction with. On an ongoing basis, global business managers will interact with their teams to get the job request effectively and efficiently analysed and performed by: $1 /$ focusing on a global project outlook; and 2/ expressing a final recommendation. 
Figure 2: Global Business Management in Market-Driven Companies

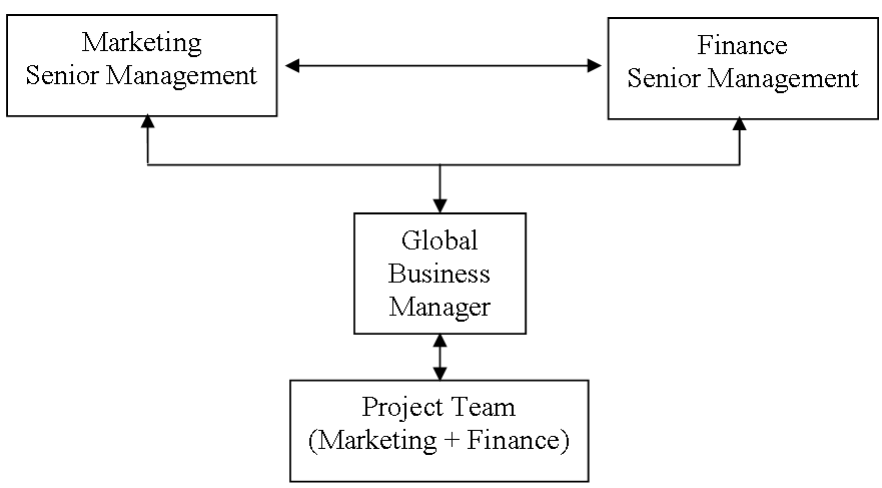

The key word in such a 'bottom up' matrix structure is interaction. It's only by embarking on a global strategic approach, like the one set out above as an illustrative example, that a fast-moving, mass-market global company will be able to continue outperforming its rivals by retaining, sustaining and differentiating its strategic competitive advantage in a Market-Driven corporate environment. 